\title{
Letter from the editor: Volume 6 (2013) best papers were selected
}

๑) Tsinghua University Press and Springer-Verlag Berlin Heidelberg 2014

I am pleased to announce that the following two papers have received Building Simulation's Best Paper Awards for Volume 6 (2013):

- Zheng O’Neill, Bryan Eisenhower (2013). Leveraging the analysis of parametric uncertainty for building energy model calibration. Building Simulation, 6(4): 365-377.

- Thierno M.O. Diallo, Bernard Collignan, Francis Allard (2013). Analytical quantification of airflows from soil through building substructures. Building Simulation, 6(1): 81-94.

Selection of the best papers is based on nominations from the Journal's editorial board members and the recommendation of an award selection committee consisting of Khee Poh Lam (chair), John Little, and Tengfang Xu. I would like to thank them for their time and effort to identify the winners among many excellent papers published in 2013.

In the past few years, Building Simulation has been expanding rapidly. And so are our authors, reviewers, and readers. As always, we want to hear from you about the Journal. Please do drop me a few lines and tell us your own experience about Building Simulation. In particular, we want to know how you view the general quality of the papers published, are they useful to your research or practices? What topics are missing in your opinion? To our authors and reviewers, please also share your experience about the usefulness of peer review comments, the speed of review and publication process, and any comments you want to give us. From time to time, our office receives requests asking for copies of papers. We cannot honor such requests because Building Simulation is not an open access journal. However, I would strongly encourage you to check with your libraries and if not yet done so, ask to subscribe. Because this is a fairly new journal, your librarians may not even know it unless you tell them.

Building Simulation is always for you.

Xudong Yang

Editor-in-Chief

Department of Building Science

School of Architecture

Tsinghua University, Beijing 100084, China

E-mail: bsjournal@tsinghua.edu.cn 